editorial / ROSS JENNER

\title{
Presence
}

Over the past decade or so, initiatives have emerged to recover some form of presence against a global culture that, largely through electronic technology, has become more and more perfectly "Cartesian". We now seem, however, to be at the beginning of a situation where new presence elements in our everyday world are recovering some ground, and there is a growing emphasis on the physical, material, performative and atmospheric-rather than meaning and semiotics. Materiality and its effects have come to assume what Hans Ulrich Gumbrecht, terms a "non-hermeneutic" presence (2004: 1-20). Today, we no longer believe that a complex of meanings can be kept separate from its medium of presentation, that is, from material. Neither is pure manipulation of data, without aesthetic and bodily intention, able to produce architecture. The material and the immaterial are not easily divided.

While presence concerns communication, it concerns space even more-through its occupation (or dis-occupation) and activation. Gumbrecht reminds us that, what is "present" to us (in the sense of the Latin prae-esse), is "in front of us, in reach of and tangible for our bodies" (17). He reminds us also of George Steiner's remarks that the arts, "wonderfully rooted in substance, in the human body, in stone, in pigment, in the twanging of gut or the weight of wind on reeds", begin, but do not end, in immanence. The task of the aesthetic is to "quicken into presence the continuum between temporality and eternity, between matter and spirit, between man and 'the other'” (Steiner, 1989: 227).

Absence of presence is not the same as presence of absence, in which traces, silences or voids powerfully embody (and make present) something not present. For example: the voids of Berlin as captured by Daniel Libeskind and Peter Eisenman; or the voids of Eduardo Chillida, Jorge Oteiza and Tadao Ando; the silence of John Cage and the $m \bar{a}$ of Toru Takemitsu. They all involve experience and affect. By contrast, representation seems to be involved with the "age of the sign" and "conceptual deduction" as Gumbrecht asserts (2004: 57).

However, for Jean-Luc Nancy in France, representation "is as old as the West", and maybe there is "no humanity (and, perhaps, no animality) that does not include representation" (1993: p. 1). Nancy's conception of presence does not refer to a permanent state, but to nascence: "Presence itself is birth, the coming that effaces itself and brings itself back" (5). Gumbrecht relates this wavering to the 
double movement of withdrawal and unconcealment in Martin Heidegger, particularly in relation to his account of a Greek temple in terms of presence via the notions of "earth" and "world". Here, "the sheer presence of the temple triggers the unconcealment of a number of things-in their thingness - that surround the temple” (2004: 73).

For Nancy the very act and pleasure of drawing, insofar as it is "the opening of form” (p. 1), is also a nascence. What would it mean for a drawing, building, artwork or poem to perform or keep alive the performance of its birth? Perhaps the malleability of Alvaro Siza's works (see Molteni, 2003), which retain the 'life' of their first sketches, or Lemi Ponifasio's irruptive choreography (Ponifasio, 2009) provide some hints to the potential of works in statu nascendi.

In addition, a human tendency to endow buildings and artworks with life includes practices involving the holy and tapu, such as sacrifice, rites of foundation and the address to a living ancestor (in whare and fale, for example). These practices frame, stage and enact the effect of "living presence"-exceeding a disinterested aesthetic contemplation of art's formal qualities (Eck, 2015: 172).

"Studying what makes viewers deny the representational character of art," argues Caroline van Eck, "will help understanding why art is such a universal feature of human life" (209). After all, "aesthetic experience" provides feelings of intensity unknown in specific everyday worlds for there is no aesthetic experience without presence effects emerging seemingly out of nowhere. Such tendencies raise the question of the relationship between life and presence, the ways in which both dimensions metabolically participate in our material environment and multiple modalities of incarnation in the arts.

In all fields of art practice, we are led to ask what part presence plays, particularly the status of presence in virtual reality and digital representation obsessed with verisimilitude. How can even purposeful design, particularly in an era of parametricism, retain an element of the status nascendi, as unprogrammed (or even unprogrammable) emergence? As Nancy finds, the "joy of averring oneself to be continually in the state of being born-a rejoicing of birth, a birth of rejoicing" requires an acceptance, even embrace, of the fact that existence "comes nude into the world" (2004: back cover).

This issue derives from the symposium on the theme of presence accompanied by a colloquium, led by Sir Harold Marshall, which took place in Auckland on Thursday, Friday and Saturday 12-14 July 2018 at which Hans Ulrich Gumbrecht was keynote speaker.

\section{Reviewed papers}

The first four reviewed papers treat the theme of making absence present in space and process. In "Between Presence and Absence: Phenomenal Interstitiality in Eisenman's Guardiola House,” Adrian Lo examines Peter Eisenman's treatment of architecture as a form of text which can be read through traces of presence and absence generated by his design process. While the notion of the trace has been examined by scholars already, it has largely been overlooked in the Guardiola House, an un-built project dating from 1988. It is here that Lo finds the trace developed particularly in terms of the interstitial, proposing that a framework focused here can present novel strategies in notation for recording and indexing 
instances of absence and presence. Lo proposes, further, that the Guardiola House presents a critical shift in Eisenman's work. Here, for the first time, he explored the trace in three dimensions as a condition of the interstitial enacted through operations of imprinting. This not only brought about the merging of constituent geometries but also provided a new way of blurring spaces (and even concepts) to constitute what might be termed a 'phenomenal' state of the interstitial, consistent with the distinction Rowe and Slutzky made between 'literal' and 'phenomenal' transparency. The house reflects Eisenman's shift from the rulebound transformations framed by Structuralism to the complex and unpredictable "events" of Post-structuralism.

In "Ex Uno Lapide: a Making Present of Absence", Konrad Buhagiar, Guillaume Dreyfuss and Ephraim Joris discuss a drawing protocol, which they term the "monolith drawing", whereby an architectural figure is extracted from a single volume, synchronising analogical with digital thinking to enter history through our capacity to long for, and hence experience, something absent. Lacan assumes there cannot be absence in an objective world, since absence can only exist through symbolic or representative means. Thus, the authors argue, it is through the representational means of the monolith drawing that architects are enabled to design presence where there is none. Hence, they explore and (re)deploy the notion of ex uno lapide in contemporary architectural production. Such creative practice recovers a tradition linking geology with architectonic drawing, and operating in conceptual space through means of contained sets of formal operations to generate a particular kind of architecture. The monolith drawing is here explained in relation to the design of a museum extension to house a tapestry cycle by Peter Paul Rubens, adjacent to St John's Co-Cathedral in Valletta. These tapestries represent the idea of transubstantiation. In response, the museum design acts as a closed vessel, a monumental reliquary, enabling a closed and controlled environment to ensure the conservation of the artwork. The reliquary is interpreted as a container of meaning, directing a reciprocal gaze towards the idea of meaningful absence. The monolith drawing installs two important principles. The idea of the mirror construct, in which an object is depicted using parallel lines to project its mirror image and allow twofold vision, outwards (res extensa) and inwards (res cogitans); and the idea of ex uno lapide-a strategy where architecture is carved out of solid mass. This carving is guided by allowing the depicted object and its mirror image to intersect. Its transcriptions allow for a drawing with history; a tracing of its own tracing.

Simon Twose and Jules Moloney, in "Drawing Canyon: Sfumato Presences in Drawing and Landscape", propose that architectural drawing can involve the merging of multiple presences. The permanent interruption, tension and intensity of mark-making, here merges with intensities in what the marks draw, be it architectural space or landscape. Their paper reports on "Canyon", a hybrid drawing project that intensifies drawing's capacity for smudged presences. Canyon attempts to develop an ever-emergent, nascent architecture from presences in drawing and landscape. The first stage of "Canyon" was exhibited at the Palazzo Bembo in the XVI Venice Biennale. It draws atmospheres from the dynamic undersea landscape of Kaikōura Canyon, Aotearoa/NZ, using a hybrid of hand sketches, soundscapes and virtual reality to distil architectural possibilities from the canyon's vast body of water, recently jolted by huge forces in the 2016 Kaikoura earthquake. This landscape is known through instrumental descriptions: sonic scans, digital models and scientific data. Less easy to record, 
however, is its powerful and ominous presence. The canyon has unimaginable mass and scale, with water kilometres deep and is figured by seismic jolts, turbid flows, pressures and intensities. "Canyon" imaginatively projects into this unseen landscape, crossing its ominous presence with evocative graphite sketches, soundscapes and the canyon-like boundlessness of virtual reality. This work proposes hybrid drawing as an open medium figured by blurred presences. It resonates with Jean-Luc Nancy's notion of drawing as the opening of form, indicating "the traced figure's 'essential incompleteness, a non-closure or non-totalizing of form'” (2013: 1). They extend the openness of gestural sketching to the digital and sensorial, and argue that VR, and sound, can be sketch-like: they too are figured by "recalcitrant, 'meaningless' smears and blotches” (Elkins, 1995: 860). They argue that such hybrid, "non-semiotic" marks draw presences, blurred presences, making evident an architecture of nascence.

Stepan Vaneyan's “Jantzen and Sedlmayr: Diaphaneia-An Impossible Presence?" examines the notion of "diaphanous structure" as a correspondence between the structure of ritual in Gothic architecture, which realises the holy presence symbolically, and that of the cult space, where experience of theophany is made manifest visually. Hans Jantzen first introduced his programmatic theory of "diaphanous structure" (diaphane Struktur) with the term "diaphaneia" in his 1927 article "On Gothic Church Space” ("Über den gotischen Kirchenraum"). By that time the word had been used in near-esoteric circles (from Jacob Boehme to Pierre Teilhard de Chardin) and in Joyce's Ulysses, 1922. Jantzen's seminal article is dedicated to the space of the Gothic cathedral, which he sees as a ritual-liturgical and multi-layered space that has, he argues, a "diaphanous structure". In his late texts, from the 1950 and 1960s, he explored "diaphaneia" as a universal way of keeping in view the horizon of the invisible presence. Most importantly, Jantzen's "diaphanous structure" informs all levels of the Gothic cathedral-from the walls of the nave to the stained glass, in other words, to colour. In his paper, Vaneyan contrasts Jantzen's "diaphaneia" with that of Hans Sedlmayr's in The Origins of the Cathedral (Die Entstehung der Kathedrale), 1951, noting that whilst for both the term presupposes the transcendent, for Jantzen this transcendence concerns space, whereas for Sedlmayr it concerns corporeality-for instance, in the vertical and the weightless canopy (baldachino) that enters the church space from above. This leads Vaneyan to question whether " $d i$ aphaneia" might be merely a means of "spiritualisation" of both the cathedral per se and of architectural theory. Further, he questions whether a "mnémotechnique" is enough to ensure the presence of the other or does it become a sign of its absence? While architecture keeps silent, an architectural theorist speaks-or, using Derrida’s words, “diaphaneia” becomes “diaphonia” (2011).

A further reviewed paper addresses the issue of presence in relation to built heritage. In "Heritage \& Persistence: The Case of the Kaiapoi Fragment", Andrew Douglas and Nicola Short consider a small surviving portion of the Kaiapoi Woollen Company Building, a warehouse and offices constructed in central Auckland, Aotearoa/New Zealand, in 1913. Known as the Kaiapoi fragment, the incongruity of this persisting building element was foregrounded in 2017, when the Griffiths Holdings Building, a plain deco, two-story commercial building immediately adjoining it, was demolished to make way for an underground station. A small portion of the Kaiapoi Woollen Company Building, itself demolished in 1964, had inadvertently remained fused to the party wall of the Griffiths Holdings Building. It was this that was left standing incongruously with the 
removal of the latter. For Douglas and Short, this tenuous persistence prompts broader questions, not only about the constitution of the present and future by cultural heritage, but also about the precarity of the contemporary present tout court. In particular, they link this precarity to Gumbrecht's (2004 and 2014) recognition of an emerging, yet still undefined, post-historicist chronotope. As Gumbrecht argues, if the preceding, historicist chronotope was characterised by a "narrow present", one in which passing historical time provides immediately cogent bearings for acting on, and organising, an impending future, our current present, "inundated by memories and objects form the past", themselves shorn of organising metanarratives, posits a truncated future, one distanced from the present, itself stalled and broadening inordinately (2014: 54-55). In their paper, Douglas and Short follow Gumbrecht's use of the chronotope to account for this compounded nature of the present and the past, a notion in fact developed by Mikhail Bakhtin to describe particular fusions of space and time evident across the history of the novel (see Bakhtin and Holquist, 2000). To better grasp the potential of Gumbrecht's claims, they explore what for Bakhtin underwrites the chronotope-dialogical exchange. In turn, they examine a particular aspect of dialogue developed by Henri Bergson (1935/1991), who himself tied such exchange to a foundational agent capable of dissolving all spatio-temporal amalgamation-duration. As a consequence, they are led to ask how Bergson's broader emphasis on the "primacy of memory' over a 'primacy of perception"” (Lawlor 2003: ix) might assist in reworking Gumbrecht's notion of presence in heritage contexts. Following Leonard Lawlor's recognition of a "non-phenomenological concept of presence" in Bergson (x), the authors attempt a provisional anatomy of presence, one prompted by-despite its diminutive scale-the Kaiapoi fragment itself.

The remaining reviewed paper considers absence in relation to place. In "Absence, Silence, and the Shades of Takemitsu's $M a$ in Venice", Felipe Lanuza Rilling proposes a dialogue between absence and silence, specifically between his own interpretations of absence through layered images and silence as it features in the musical works by Töru Takemitsu. His layered images seek to re-present experiences of absence as they appear to the senses in the built environment. They respond to what he sees as the capacity of absence to evoke multiple, uncertain and distant presences that seem to be away from our grasp. In Takemitsu's multi-layered and seemingly unstructured pieces, silence plays a key role in bringing about $m a$, which refers to a meaningful spatio-temporal gap, interval or in-between condition, often invested with metaphysical connotations of great significance in Japanese culture. Following a hint by composer Philip Dawson, the advice of musical interpreter Cristián Alvear, and largely driven by intuition, Rilling explores the albeit distant resonances of his visual work in the acclaimed Japanese composer's music. In this way, he expands the interpretative possibilities of absence and layering in representing the vanishing atmospheres of Venice, an example of fragile existence and aggregated formation.

\section{Postgraduate creative design research}

In a reviewed design research paper arising out of a Master of Architecture (Professional) degree at Victoria, University of Wellington, Nina Boyd examines the relationship between architecture and the tourist experience. In her project titled, "Staging Tourism: Performing Place", Boyd argues that in architecture the 
corporeality of the tourist is typically reduced to acts of viewing. Contrastingly, her project explores and devises multiple acts of mobilisation to force a paradigmatic shift from the "gaze" to "performance". Privileging sensuous experiences and active choreography, the project investigates how architecture can stage and amplify the multiplex performances of tourism in order to produce more complex accounts and experiences of place. Utilising a "design through research" methodology, the design proposition is developed through iterative design experiments enacted across three increasing scales: the first engaging with the human scale through 1:1 installation; the second testing the performative dimensions of tourism as embodied programmatically via hotel design; and, the third testing the nature of tourism's public performance through the design of an artificial island for Wellington's Shelly Bay.

\section{Reviews}

Completing the issue are three book reviews. The first, by John Dixon Hunt, considers Anuradha Chattergee's, John Ruskin and the Fabric of Architecture (2017) published by Routledge Press. The second, by Carl Douglas, addresses Marian Macken's, Binding Space: The Book as Spatial Practice (2018) also released by Routledge Press. The third, by Mark Jackson, engages with Farzaneh Haghighi's, Is the Tehran Bazaar Dead? : Foucault, Politics, and Architecture (2018) pub-lished by Cambridge Scholars Publishing.

Finally, the adventure into presence carried by this issue may be thought, as Gumbrecht himself has subsequently characterised the symposium and colloquium that was nascent for the papers offered here, as a "desire for and first trace of a recovery of presence culture" (personal communication, 2016). Against an insistent "universe of contingency", what working on and with presence potentiates is the opening of "fault lines" in a present saturated with modes of control and drives to commodify (personal communication, 2016). Presence as erring immediacy, precisely suggests a critical counter to the insistent swathe of techniques determining contemporary attention. 


\section{REFERENCES}

Bakhtin, M., Holquist, M. (Ed.)

(2000). The dialogical

imagination: Four essays by M.M.

Bakhtin (C. Emerson \& M.

Holquist, Trans.). Austin, TX:

University of Texas Press.

Bergson, H. (1935/1991). Matter and memory (N. Margaret Paul, W. Scott Palmer, Trans.). New York, NY: Zone Books.

Derrida, J. (2011). Voice and phenomenon: Introduction to the problem of the sign in Husserl's phenomenology (L. Lawlor,

Trans.). Evanston, III:

Northwestern University Press.

Eck, C. van (2015). Art, Aagency and Lliving Presence: From the Animated Image to the Excessive Object. Boston, MA: De Gruyter.

Elkins, J. (1995). “Marks, Traces,

'Traits', Contours, 'Orli', and

'Splendores': Nonsemiotic

Elements in Pictures." Critical Inquiry, Vol. 21, No. 4, 822-860.

Gumbrecht, H. U. (2004).

Production of presence: What

meaning cannot convey. Stanford, CA: Stanford University Press.

Gumbrecht, H. U. (2014). Our broad present: Time and contemporary culture. New York, NY: Columbia University Press.

Jantzen, H. (2000). Über den gotischen Kirchenraum und andere Aufsätze, Berlin: Mann [originally Freiburger

Wissenschaftliche Gesellschaft, Heft 15, Freiburg in Breisgau, 1928].
Lawlor, L. (2003). The challenge of Bergsonism. London, UK: Continuum.

Nancy, J. L. (1993). The birth to presence (B. Holmes, et. al., Trans.). Stanford, CA: Stanford University Press.

Nancy, J. L. (2013). The pleasure in drawing (P. Armstrong, Trans.). Oxford, UK: Oxford University Press.

Ponifasio, L. (2009) Tempest: Without a body [performance] Retrieved from https://www. youtube.com/ watch?v=WfLqv85uCww\& feature=player embedded

Molteni, E. (2008). Comme un sculpteur, on doit maintenir l'argile humide. Casabella, 763, 11 .

Reverb. (2016). Kaiapoi Building Fragment heritage report. Unpublished report commissioned by Auckland Transport.

Steiner, G. (1989). Real presences: Is there anything in what we say? London, UK: Faber. 